\title{
Validity and Reliability of Turkish Version of Deprivation in Primary Care Questionnaire (DiPCare-Q)
}

\author{
Birinci Basamak Sağlık Hizmetlerinde Yoksunluk Anketinin (DiPCare-Q) \\ Türkçe Geçerlik ve Güvenirlik Çalışması
}

\author{
Fikriye Yılmaz* ${ }^{1}$, Burcu Yılmaz ${ }^{1}$
}

\section{ÖZET}

\begin{abstract}
Amaç: Çalışmanın amacı Birinci Basamak Sağlık Hizmetlerinde Yoksunluk Anketinin (DiPCare-Q) Türkçe geçerlik ve güvenirliğini test etmektir. Yöntem: Araştırmada sosyo-demografik bilgiler, yaşam standardı göstergeleri ve DiPCare-Q Türkçe formundan oluşan anket Ankara ili Akyurt ilçesinde Aile Sağlığı Merkezine başvuran 18 yaş ve üstü toplam 160 kişiye yüz yüze görüşme yöntemi ile uygulanmıştır. Ölçeğin geçerliği; kapsam geçerliği, yapı geçerliği ve yordama geçerliği ile değerlendirilmiştir. Ölçeğin güvenirliğini test etmek için iç tutarlılık ve düzeltilmiş madde-toplam korelâsyonu katsayıları hesaplanmıştır. Bulgular: Araştırmaya katılan 160 kişinin \%61,3’ü kadın, \%74,4'ü evli, \%62,5'i lise altı eğitimlidir. Ölçeğin kapsam geçerliği değerlendirmesinde uzman görüşleri arasındaki uyum için yapılan Kendall's W sayıs1 0,441 ve $p<0,05$ olarak hesaplanmıştır. Ölçeğin yapı geçerliği için yapılan temel bileşenler faktör analizi sonuçları DiPCare-Q'nun 3 faktör ile toplam varyansın \%68,49'unu açıkladığını göstermektedir. Yordama geçerliği için yoksulluğun nesnel göstergelerine göre DiPCareQ toplam ve alt boyut puan ortalamaları karşılaştırılmış; DiPCare-Q'nun maddi yoksunluk boyutu, sosyal yoksunluk boyutu ve toplam puan ortalamaları yoksulluğun nesnel göstergelerine istatistiksel olarak anlamlı farklılık gösterdiği belirlenmiştir $(p<0,05)$. Ölçeğin güvenirliğinin değerlendirilmesinde incelenen Kuder-Richardson 20 katsayısı 0,80 olarak hesaplanmış, ölçeğin güvenilir olduğu sonucuna ulaşılmıştır. Ayrıca maddelerin toplam puanla korelâsyonları da standart değer 0,40 'ın üzerinde belirlenmiştir. Sonuç: Çalışma sonucunda DiPCare-Q Türkçe versiyonunun geçerli ve güvenilir olduğu belirlenmiş ve birinci basamak sağlık hizmetlerinde kullanımı önerilmiştir.
\end{abstract}

Anahtar kelimeler: Yoksulluk, sağlık hizmetleri, geçerlik güvenirlik, kültürel uyarlama

\begin{abstract}
Objective: The aim of this study is to test the validity and reliability of Turkish version of Deprivation in Primary Care Questionnaire (DiPCare-Q). Method: In the study, a survey, consisting of socio-demographic information, living standard indicators and DiPCare-Q Turkish form, was applied with face to face interviews to 160 people who are literate, older than 18 years age and applied to Family Health Center in Akyurt district of Ankara. The validity of the scale was assessed by content validity, construct validity and discriminant validity. To test the reliability of the scale, internal consistency and item total correlation coefficients were calculated. Results: $61.3 \%$ of the participants were women, $74.4 \%$ were married and $62.5 \%$ were under high school. In the content validity, Kendall's Coefficient of Condordance W was calculated as 0,441 and p <0,05. In construct validity, the results of Principal component analysis showed that the model explained $68.49 \%$ of the total variance with 3 factors. For dicriminant validity, DiPCare-Q total and subscale scores of participants were compared according to objective indicators of poverty. And it was determined that there were statistically significant differences in scores of social deprivation dimension, material deprivation dimension and total DiPCare-Q according to objective indicators of poverty DiPCare-Q. In the evaluation of reliability of scale, the Kuder-Richardson 20 coefficient was calculated as 0,80 which is the result that the scale is reliable. In addition, correlations of the items with the total score were determined above the standard value of 0.40. Conclusion: The results of the study showed that Turkish version of DiPCare-Q is valid and reliable, so its usage was recommended in primary care services.
\end{abstract}

Keywords: Poverty, health services, validity reliability, cultural adaptation.

Received / Geliș tarihi: 14.02.2017, Accepted / Kabul tarihi: 29.03.2017

${ }^{1}$ Başkent Üniversitesi Sağlık Bilimleri Fakültesi Sağlık Yönetimi Bölümü

*Address for Correspondence / Yazışma Adresi: Fikriye Yılmaz, Başkent Üniversitesi Sağlık Bilimleri Fakültesi Sağlık Yönetimi Bölümü Bağlıca Kampüsü, Ankara-TÜRKIYEE-mail: fyilmaz@baskent.edu.tr

Yılmaz F, Yılmaz B. Birinci Basamak Sağlık Hizmetlerinde Yoksunluk Anketinin (DiPCare-Q) Türkçe Geçerlik ve Güvenirlik Çalışması.TJFMPC,

2017;11(2): 79-87.

DOI: $10.21763 /$ tjfmpc.317738

Y1lmaz ve Y1lmaz, TJFMPC www.tjfmpc.gen.tr 2017; 11 (2) 


\section{GíRIŞ}

Ekonomik ya da sosyal boyutlu gelişmelere paralel olarak ortaya çıkan yoksulluk olgusu, 1990'lı y1llardan itibaren küresel bir tehdit olarak görülmektedir. İki bin on beş yılı itibariyle dünya nüfusunun $\% 15$ 'i günlük sadece bir dolarlık bir gelire sahip iken; her üç kişiden biri günde iki dolar ve altında bir gelirle yaşamını sürdürmek durumundadır. Dünya Sağlık Örgütüne göre yoksulluk günümüzde birçok hastalık ve ölümün en büyük nedenidir. İlk kez 1820 'lerde kaleme alınan "yoksulluğun sağlık üzerinde çok ciddi etkileri olduğu" düşüncesi ${ }^{1}$ geçen yüzyılda yoksulluk sağlık etkileşimini irdeleyen çok sayıda bilimsel araştırma $^{2-5}$ ile de kanıtlanmış durumdadır. Dünyada yoksulluk yüzünden her gün 22 bin çocuk hayatını kaybetmektedir. İki bin on iki yılı itibariyle, hala 748 milyon insan içme suyu kaynaklarına, 855 milyon insan da temel sağlı hizmetlerine ulaşamamaktadır. ${ }^{6}$

Yoksulluk genel olarak, insanların refahı için ekonomik, sosyal ve diğer standartları karşılayamaması olarak tanımlansa da düşük sağlık düzeyi, eğitim düzeyinin yetersizliği, kötü beslenme, güçsüzlük ve sosyal dișlanma gibi unsurlarla etkileșim içerisinde olan karmaşık ve çok boyutlu bir olgudur. ${ }^{3}$ Ekonomistler ve politikacılar 1960'l1 yıllarda, "bir kişinin maddi yaşam standardının büyük ölçüde refahını belirlediği” varsayımına dayanan yoksulluğun parametrik ölçümüne odaklanmışlardır. $^{7} \mathrm{Bu}$ yaklaşım doğrultusunda yoksul kişileri; yoksulluk sınırı olarak adlandırılan belirli bir sınırın altında gelir veya harcama şeklinde ölçülen maddi yaşam standartlı ailelerde yaşayan kişiler olarak tanımlamışlardır. ${ }^{7}$ Gelir yetersizliği, sosyal dışlanma, eğitim durumu, çevre koşulları, fiziki engeller vb. gibi unsurları da kapsayan yoksulluk tanımları ve ölçümleri 1970'li yılların sonlarında geliştirilmeye başlanmıştır. Amartya Sen, 1980'li yılarda yayımladığı bir dizi yazısındaki geliştirilen kapasite yaklaşımıyla ${ }^{8-9}$ yoksulluğu, ekonomik olarak değerlendirmenin ötesinde sağlık ve eğitim hizmetlerine ulaşımı ve daha kapsamlı olarak yaşam kalitesini de içeren "kapasite yoksunluğu" olarak değerlendirmektedir. ${ }^{10}$ Bin dokuz yüz doksanlı yılların başlarında Townsend, yoksunluk kavramını kaynaklardan ziyade koşullara uygulamış ve yoksunluk ve yoksulluk arasında bir ayrım yapmıştır. Yoksunluk kavramını; "birey, hane ya da grupların genel toplum veya ülke seviyesine göre gözlenebilir ve kanıtlanabilir dezavantajlı durumda olmaları" olarak tanımlamıs ve yoksunluğu maddi ve sosyal olarak ikiye ayırmıștır. Aynı zamanda yoksunluğun sağlikta eşitsizliklerin temel nedeni olduğunu ifade etmiş ve belli bir coğrafik alanda yoksunluğu ölçmek için bir indeks geliştirmiştir. Townsend yoksunluk indeksinin ardından bu amaçla geliştirilen bazı indeksler;
Jarman Az Gelişmiş Bölge Skoru, Carstairs Yoksunluk İndeksi, MATDEP (açılımı) ve SOCDEP (açılımı yazılmalı), Çoklu Yoksunluk İndeksi ve İtalyan Önerisi olarak sayllabilir. Yoksunluk indekslerinde, yoksunluk ile düşük sağlık statüsü arasındaki ilişkinin araştırılmasında ve sağlık programları ve hizmetleri için yapılacak kaynak tahsisinin belirlenmesinde kullanılmaktadır. ${ }^{11}$

Son yıllarda sağlık alanında yapılan araştırmalarda yoksulluğun ölçülmesi ile ilgili çeşitli araçlar önerilmektedir. Çoğu tıbbi araştırmada gelir, mesleki durum ve eğitim düzeyini içeren yoksulluğun nesnel göstergelerine (geleneksel ekonomik göstergeler olarak da adlandırılır) odaklanılmıştır. Ancak bu geleneksel ekonomik göstergeler sadece yoksulluğun tek bir yönünü ifade eden maddi yoksunluğu değerlendirmesi, objektif sosyoekonomik durumun her zaman sübjektif sosyoekonomik duruma eşit olmaması ve bu göstergelerin sadece "kaynaklara" odaklanarak bireylerin kaynakları değere dönüştürme becerilerini yok sayması gibi nedenlerle eleştirilmektedir. ${ }^{12} \mathrm{Bu}$ nedenle dünyada sağlık alanında kullanılan yoksulluk ölçümlerinde gelinen son noktada toplumsal düzeyde yoksunluğun ele alınmasından ziyade bireysel düzeyde maddi ve sosyal yoksunluklara odaklanılmaktadır. Bu alanda yapılan araştırmalarda da yoksulluğun çok boyutlu yönlerini tespit etmek üzere bazı ölçekler geliştirilmiştir. Yeni Zelanda'da geliștirilen NZiDep (New Zealand Index of Socioeconomic Deprivation for Individuals), Fransa'da Sağlık Değerlendirme Merkezlerinde kullanılmak üzere geliştirilen EPICES (Evaluation of Deprivation and Inequalities in Health Examination Centres) skor, Eroğlu tarafindan geliştirilen Ağırlıklandırılmış Yoksunluk İndeksi, İsviçre'de geliştirilen DiPCare-Q (Deprivation in Primary Care Questionnaire) ve Fransa'da acil servislerde kullanılmak üzere geliştirilen PQoL-Q (Poverty Related Quality of LifeQuestionnaire/Yoksulluğa Özgü Yaşam Kalitesi Ölçeği) yoksulluğun çok boyutlu bir olgu olduğunu dikkate alarak tasarlanmış en güncel yoksunluk ölçekleridir. Yeni Zelenda'da geliştirilen NZiDep Yeni Zelanda'ya özgü kültürel öğeler içermesi ve yoksunluğun daha çok maddi boyutuna odaklanması nedeniyle, Eroğlu tarafından geliştirilen indeks sadece maddi yoksunluğa odaklanması nedeniyle, EPICES skor ise ağırlıklı olarak sosyal yoksunluk ile ilgili maddeler içermesi ve diğer araçlarla kıyaslandığında iç tutarlılığı daha düşük olması nedeniyle eleştirilmektedir. ${ }^{13}$ Yoksulluğa Özgü Yaşam Kalitesi Ölçeği ise yoksulluğu tek başına belirlemekten ziyade parametrik göstergelerle birlikte kullanılarak yoksul bireylerin yaşam kalitesini belirlemeyi hedefleyen bir ölçektir. ${ }^{12} \mathrm{Bu}$ çalışmada birinci basamak sağlık hizmetlerinde maddi ve sosyal yoksunluğu belirlemek üzere geliştirilmiş çok boyutlu DiPCare-Q'nun Türkçe 
geçerliğini ve güvenirliğini test etmek amaçlanmıştır. Hastaların mutlak ve göreli yoksunluk durumlarının belirlenmesi sağlıkta eşitsizliklere yönelik sosyal müdahaleler geliştirmenin ilk adımı olarak değerlendirilebilir. Geçerli bir bireysel yoksunluk indeksinin, sağlığın sosyal özelliklerle ilişkisini belirleyebilmeleri için sağlık çalışanları, yöneticileri ve sosyal hizmet uzmanları için temel bir araç olacağı düşünülmektedir.

\section{YÖNTEM}

\subsection{Araştırmanın Evren ve Örneklemi}

Metodolojik araştırma olarak planlanan bu çalışmanın evrenini Ankara ili Akyurt ilçesinde 2 no.lu Aile Sağlığı Merkezinden (ASM) sağlık hizmeti alan 18 yaş ve üstü kişiler oluşturmaktadır. Akyurt ilçesinin seçilmesinin nedeni; Ankara Kalkınma Ajansı desteğiyle 2012 yılında gerçekleştirilen “Ankara'nın Kentsel Yoksulluk Haritası" projesi sonuçlarına göre Ankara'da göreli yoksulluğun \%36,5 ile en yüksek olduğu ilçe olmas1 ve yoksulluk riskinin en yüksek olduğu ilçeler arasında olmasıdır. ${ }^{14}$ Çalışmanın örneklem büyüklüğü, literatürde ölçeklerin psikometrik özelliklerinin değerlendirilmesinde örneklem büyüklüğünün madde sayısının 10 katı olması önerisi ${ }^{15}$ dikkate alınarak toplam 160 kişi olarak belirlenmiştir. Örnekleme dahil edilen 160 kişi, 15 Mart-30 Mart 2016 tarihleri arasında ASM'ye başvuran ve araştırmaya katılmayı kabul eden kişilerden kolayda örnekleme yöntemi ile seçilmiştir.

\subsection{Veri Toplama Araçları}

Araştırma verileri; üç bölümden oluşan anket formu ile toplanmıştır. Anket formunun birinci bölümünde katılımciların sosyo-demografik bilgilerini belirlemeye yönelik 12 soru yer almaktadır. İkinci bölümde Türkiye İstatistik Kurumunun (2015) Gelir ve Yaşam Koşulları Araştırmasında maddi yoksunluğu belirlemek üzere kullandığı yaşam koşulu göstergeleri yer almaktadır. $\mathrm{Bu}$ maddeler; konut masrafları, borç ve taksit ödemeleri, beklenmedik harcamalar, evden uzakta bir hafta tatil, evin 1sınma ihtiyacı, iki günde bir et, tavuk, balık içeren yemek masrafi, yıpranmış veya eskimiş mobilyaları yenileyebilme, yeni giysiler alabilmedir. Maddi yoksunluk; sayılan maddelerden en az 4 tanesini ekonomik nedenlerle karşılayamayan/mahrum olan insanların oranı olarak tanımlanmıştır. ${ }^{16}$ Anket formunun son bölümünde Vaucher ve arkadaşları (2012) tarafindan birinci basamak sağlı hizmetlerinde yoksunluğun belirlenmesi amaciyla geliştirilen DiPCare-Q yer almaktadır. DiPCare-Q; maddi, sosyal ve sağlık yoksunluğu boyutları ile ilgili toplam 16 sorudan oluşan ve evet/hayır şeklinde cevaplanan bir ölçektir. Ölçekte maddi yoksunluk boyutunda sekiz $(1,2,3,4,5,6,10,13$. maddeler), sosyal yoksunluk boyutunda beş $(7,8,9,11$ ve 12 . maddeler) ve sağlık yoksunluğu boyutunda üç (14, 15 ve 16. maddeler) soru bulunmaktadır. Ölçekte yer alan maddelere verilen yanıtlar evet 1 , hayır 0 olarak puanlanmıştır. $7,8,9,11$ ve 12 . maddeler ters kodlanmıştır. Her bir alt boyut puanı, boyutta yer alan maddelerin toplam puanı ile hesaplanmıştır. Toplam indeks puanını hesaplamak için alt boyutlar aşağıdaki kategorilere ayrılmıştır: ${ }^{13}$

Maddi yoksunluk kategorileri: 1-2 puan: 1, 3-6 puan: 2, 7-8 puan: 3

Sosyal yoksunluk kategorileri: Sosyal yoksunluk indeksi

Sağlık yoksunluğu kategorileri: 0-1 puan: 0, 2-3 puan: 1

Doğrusal regresyon yöntemiyle belirlenen aşağıdaki formül kullanılarak her katılımeı için toplam yoksunluk indeksi hesaplanmış ve en yakın tam sayıya yuvarlanmıştır;

\section{DiPCare İndeksi =}

0.810*(Maddi Yoksunluk Kategorisi)

$+0.455^{*}$ (Sosyal Yoksunluk Kategorisi)

$+0.711 *$ (Sağl1k Yoksunluğu Kategorisi)

Ölçeğin toplamından ve alt boyutlarından alınan yüksek puan yoksunluğun arttığını göstermektedir. Vaucher ve arkadaşları (2012) tarafından yapılan çalışmada DiPCare-Q İndeksinin test-tekrar test iç tutarlılık katsayısı 0,847 olarak hesaplanmış, kapsam geçerliğinde uzman görüşleri ölçeğin alt boyutlarında uygunluğunu ortalamanın üstünde değerlendirmiş ve uyum geçerliğinde tüm alt boyutların özellikle sübjektif sosyal durumla ilişkili olduğu belirlenmiştir. Orijinal çalışmada ölçeğin İngilizce, Fransızca, Almanca ve İtalyanca versiyonları kullanılmış ve ölçeğin kullanıma açık olduğu ifade edilmiştir. ${ }^{13}$

\subsection{Veri Toplama Süreci}

Çalışmada veri toplama sürecinde ilk olarak Akyurt ilçesinde 2 nolu ASM'nin sorumlu hekimi ile görüşülmüş, çalışmanın amacı ve yöntemi açıklanmış, araştırmanın gerçekleştirilmesi için izin alınmıştır. Gerekli izinlerin alınmasının ardından 15 Mart-30 Mart 2016 tarihleri arasında veriler toplanmıştır. Anket formu, Akyurt ilçesinde 2 no.lu ASM'ye başvuran ve çalışmaya katılmayı kabul eden, 18 yaş ve üstü, okuryazar 160 kişiye yüz yüze görüşme yöntemi ile uygulanmıştır. Katılımcılara anketler dağıtıldıktan sonra, katılımın gönüllü olduğu ifade edilmiş ve çalışmanın amacı hakkında 
bilgi verilmiştir. Anketlerin tamamlanması 10-15 dakika arasında zaman almaktadır.

$\mathrm{Bu}$ araştırma Başkent Üniversitesi Tıp ve Sağlık Bilimleri Araştırma Kurulu tarafından onaylanmış (Proje No: KA16/129) ve Başkent Üniversitesi Araştırma Fonunca desteklenmiştir.

\subsection{Verilerin Analizi}

Ölçeğin geçerliği; kapsam geçerliği, yapı geçerliği ve yordama geçerliği ile değerlendirilmiştir. Kapsam geçerliği için uzman görüşü değerlendirmesi yapılmıştır. Yapı geçerliğini belirlemek için Açıklayıcı Faktör Analizi (AFA) yapılmıştır. Yordama geçerliği için ise parametrik yoksulluk ölçümlerine göre DiPCare-Q ölçeğinin toplam ve alt boyut puan ortalamaları karşılaştırılmıştır. Ölçeğin güvenirliğini test etmek için Kuder-Richardson 20 ve düzeltilmiş maddetoplam korelâsyonu yöntemleri kullanılmıştır. Tüm analizlerde $\mathrm{p}<0,05$ anlamlılık düzeyi olarak kabul edilmiştir. Verilerin analizinde PASW 18.0 programı kullanılmıştır.

\subsection{Geçerlik Çalışması}

DiPCare-Q'nun Türkçeye uyarlama çalışması için öncelikle ölçeğin İngilizce versiyonu üç profesyonel tercüman tarafindan Türkçeye çevrilmiştir. İkinci aşamada elde edilen Türkçe formlar farklı tercümanlar tarafindan tekrar İngilizceye çevrilerek iki form arasındaki tutarlılık incelenmiştir. Elde edilen Türkçe formlar anlam ve dilbilgisi açısından değerlendirilerek tek bir form elde edilmiştir. Ölçeğin Türkçe formu 48 kişiye (ölçekteki soru sayısının 3 katı) uygulanarak net olmayan ifadeler belirlenmiş ve Ek'de yer alan ölçeğin son hali oluşturulmuştur. ${ }^{17}$

Ölçeğin kapsam (içerik) geçerliği uzman görüşü ile değerlendirilmiştir. Sağlık yönetimi, aile hekimliği ve sosyal hizmet alanlarında çalışan uzman beş öğretim üyesi tarafından ölçek maddeleri amaca uygunluk açısından incelenmiş ve üçlü derecelendirme sisteminde $(1=$ madde gerekli, $2=$ madde yararlı ancak yeterli değil $3=$ madde gereksiz) değerlendirilmiştir. Uzmanların görüşlerine göre düzeltilmesi istenilen maddeler yeniden gözden geçirilmiş ve gerekli düzeltmeler yapılmıştır. Uzman görüşleri arasındaki uyum için Kendall's W analizi yapılmıştır.

Ölçeğin yap1 geçerliği AFA ile değerlendirilmiştir. Faktör analizi için örneklem büyüklüğünün yeterliliği Kaiser-Meyer Olkin (KMO) ve Barlett testi ile analiz edilmiştir. Açıklayıcı Faktör Analizi Temel Bileşenler Analizi ve varimax rotasyon yöntemi ile gerçekleştirilmiştir.
Ölçeğin yordama geçerliği yoksulluğun objektif göstergeleri (gelir, meslek, eğitim ve maddi yoksunluk) ile ölçek toplam ve alt boyut puanları arasındaki ilişki ile değerlendirilmiştir. Ölçeğin toplam ve alt boyut puanlarının normal dağılıma uygunluğu Kolmogorov-Smirnov testi ile analiz edilmiştir ve normal dağılıma uygun olmadıkları belirlenmiştir $(p<0.05)$. İki gruplu değişkenlerde ölçek toplam ve alt boyut puanlarının ortalamalarını karşılaştırmak için Mann-Whitney U testi, ikiden fazla gruplu değişkenlerde Kruskal Wallis testi kullanılmıştır.

\subsection{Güvenirlik Çalışması}

Ölçeğin güvenirliği iç tutarlılık ve madde toplam korelasyon katsayıları ile değerlendirilmiştir. Ölçekte yer alan maddeler iki değerli ( 0 ve 1$)$ ölçümlendiği için Kuder Richardson-20 güvenirlik katsayısı kullanılmıştır. Güvenirlik katsayısı 0,40'dan küçükse ölçeğin güvenilir olmadığı, 0,40 0,60 arasında düşük, $0,60-0,80$ arasında yüksek ve 0,80 'in üzerinde olduğunda çok yüksek derecede güvenilir olduğu kabul edilmektedir. Madde toplam korelasyon katsayılarında ise maddelerin toplam puan ile korelasyonunun istatistiksel olarak anlamlı düzeyde 0,40'dan yüksek olması beklenir.

\section{BULGULAR}

Araştırmaya katılan 160 kişinin yaşları 18 ile 65 arasında dağılım göstermekte olup yaş ortalaması $39,51 \pm 13,43$ y1l olarak belirlenmiştir. Katılımcilardan \%71,9'u tedavi amaciyla, \%28,1'i ise kontrol, ilaç yazdırma, rapor alma gibi diğer nedenlerle ASM'ye geldiğini belirtmiştir. Araştırmaya katılan 160 kişinin bazı sosyodemografik özellikleri Tablo 1'de gösterilmektedir.

\subsection{Geçerlik Sonuçları}

Araştırmaya katılan 160 kişinin DiPCare-Q Ölçeği toplam ve alt boyut puanlarına ilişkin tanımlayıcı istatistikleri Tablo 2'de özetlenmiştir.

Kapsam geçerliği: Uzman görüşleri arasındaki uyum için yapılan Kendall's W sayısı 0,441 ve $\mathrm{p}<0,05$ olarak hesaplanmıştır. Uzman görüşleri arasında uyum olduğu saptanmıştır.

Yapı geçerliği: Ölçeğin yap1 geçerliğini değerlendirmek amacıyla AFA yapılmıştır. Örneklem büyüklüğünün yeterliğini gösteren KMO katsayısı 0,76 olarak bulunmuş ve Barlett test sonucunun istatistiksel olarak anlamlı olduğu belirlenmiştir $\left(\chi^{2}=787,80, \mathrm{p}=0,000\right)$. Bu sonuçlar Temel Bileşenler Analizi için korelasyon matrisinin yeterli olduğunu göstermektedir. Tablo 3'de Temel Bileşenler Faktör Analizi'nin sonuçları yer 
Tablo 1. Katılımcıların Sosyo-Demografik Özellikleri

\begin{tabular}{|c|c|c|}
\hline Değişkenler & Sayı (n) & Yüzde (\%) \\
\hline \multicolumn{3}{|l|}{ Cinsiyet } \\
\hline Kadın & 98 & 61,3 \\
\hline Erkek & 62 & 38,8 \\
\hline \multicolumn{3}{|l|}{ Medeni durum } \\
\hline Evli & 119 & 74,4 \\
\hline Bekâr/ Boşanmış/Ayrı yaşıyor & 41 & 25,6 \\
\hline \multicolumn{3}{|l|}{ Ĕgitim } \\
\hline Lise altı eğitimli & 100 & 62,5 \\
\hline Lise mezunu & 51 & 31,9 \\
\hline Yükseköğretim mezunu & 16 & 10,0 \\
\hline \multicolumn{3}{|l|}{ Meslek } \\
\hline Profesyonel meslek çalışanları & 4 & 2,5 \\
\hline Nitelik gerektirmeyen işlerde çalışanlar & 77 & 48,1 \\
\hline Ev hanımı/çalışmıyor & 79 & 49,4 \\
\hline \multicolumn{3}{|l|}{ Sosyal Güvence } \\
\hline SGK & 148 & 92,5 \\
\hline Yeşil kart & 3 & 1,9 \\
\hline Sigortasız/İşsiz & 9 & 5,6 \\
\hline \multicolumn{3}{|l|}{ Ayllk Hane Halkı Geliri } \\
\hline 1.300 TL ve alt1 & 39 & 24,4 \\
\hline $1.301-2.780 \mathrm{TL}$ & 74 & 46,3 \\
\hline $2.780-4.260 \mathrm{TL}$ & 40 & 25,0 \\
\hline 4.261 TL ve üstü & 7 & 4,4 \\
\hline \multicolumn{3}{|l|}{ Konut Mülkiyeti } \\
\hline Ev sahibi & 71 & 44,4 \\
\hline Kirac1/Diğer & 89 & 55,6 \\
\hline \multicolumn{3}{|l|}{ Herhangi Bir Kurum/ Kişiden Yardım Alma } \\
\hline Evet & 49 & 30,6 \\
\hline Hayır & 111 & 69,4 \\
\hline \multicolumn{3}{|l|}{ Maddi yoksunluk } \\
\hline Evet & 40 & 25,0 \\
\hline Hayır & 120 & 75,0 \\
\hline TOPLAM & 160 & 100 \\
\hline
\end{tabular}

\begin{tabular}{|l|c|c|c|c|c|}
\hline Tablo 2. DiPCare-Q Ölçeği ve Alt Boyutlarının Tanımlayıcı Özellikleri \\
\hline Boyut & Minimum & Maksimum & 1. çeyrek & Medyan & 3. çeyrek \\
\hline Maddi Yoksunluk & 0 & 8 & 1 & 4 & 5 \\
\hline Sosyal Yoksunluk & 0 & 5 & 2 & 3 & 3 \\
\hline Sağlik Yoksunluğu & 0 & 2 & 0 & 0 & 1 \\
\hline DiPCare-Q Toplam & 1 & 5 & 2 & 3 & 3 \\
\hline
\end{tabular}

almaktadır. Faktör analizi sonucunda ölçeğin toplam varyansın \%68,49'unu açıklayan toplam 3 faktörden oluştuğu belirlenmiştir. Tablonun son sütununda her bir faktörün DiPCare-Q'nun toplam puanı ile korelasyon katsayıları yer almaktadır $(\mathrm{p}<0.05)$. Analiz sonuçları, ölçeğin yapı geçerliğinin kabul edilebilir düzeyde olduğunu göstermektedir. 


\begin{tabular}{|c|c|c|c|c|}
\hline \multicolumn{5}{|c|}{ Tablo 3. DiPCare-Q'nun Yapı Geçerliği } \\
\hline & \multicolumn{3}{|c|}{ AFA } & \multirow{2}{*}{ Boyut } \\
\hline & F1 & $\mathbf{F 2}$ & F3 & \\
\hline Madde 1 & ,775 & & & \multirow{8}{*}{$\begin{array}{c}\text { Maddi } \\
\text { yoksunluk } \\
\left(\mathrm{r}=0,798^{*}\right)\end{array}$} \\
\hline Madde 2 & 609 & & & \\
\hline Madde 3 & 600 & & & \\
\hline Madde 4 & ,696 & & & \\
\hline Madde 5 & ,654 & & & \\
\hline Madde 6 & ,451 & & & \\
\hline Madde 10 & 621 & & & \\
\hline Madde 13 & 801 & & & \\
\hline Madde 7 & & ,560 & & \multirow{5}{*}{$\begin{array}{c}\text { Sosyal } \\
\text { yoksunluk } \\
\left(\mathrm{r}=0,716^{*}\right)\end{array}$} \\
\hline Madde 8 & & ,484 & & \\
\hline Madde 9 & & ,751 & & \\
\hline Madde 11 & & 672 & & \\
\hline Madde 12 & & 647 & & \\
\hline Madde 14 & & & 432 & \multirow{3}{*}{$\begin{array}{c}\text { Sağlik } \\
\text { yoksunluğu } \\
\left(\mathrm{r}=0,489^{*}\right)\end{array}$} \\
\hline Madde 15 & & & ,526 & \\
\hline Madde 16 & & & ,653 & \\
\hline
\end{tabular}

Yordama Geçerliği: Ölçeğin yordama geçerliğini değerlendirmek amacıyla yoksulluğun parametrik

ölçümlerine göre ölçeğin toplam ve alt boyut puan ortalamaları karşılaş̧ırılmıştır. Tablo 4'de analiz sonuçları özetlenmektedir. Tablo 4'de görüldüğü gibi DiPCare-Q'nun maddi yoksunluk boyutu, sosyal yoksunluk boyutu ve toplam puan ortalamaları yoksulluğun nesnel göstergelerine istatistiksel olarak anlamlı farklılık göstermektedir $(p<0,05)$. Aylık hane halkı geliri azaldıkça yoksunluk artmaktadır. Ayrıca lise altı eğitimliler, çalışmayanlar ya da ev hanımları, ev sahibi olmayanlar, bir kurum ya da kişiden yardım alanlar ve Türkiye İstatistik Kurumunun (TÜIK) yaşam standardı göstergelerine göre "maddi yoksun" olarak tanımlananlar arasında yoksunluğun daha fazla olduğu belirlenmiştir.

\subsection{Güvenirlik Sonuçları}

Ölçeğin güvenirliği Kuder Richardson-20 güvenirlik katsayısı ile değerlendirilmiş olup 0,80 olarak hesaplanmıştır. Ölçeğin alt boyutları için KuderRichardson korelasyon katsayıları ise maddi yoksunluk boyutu için 0,83 , sosyal yoksunluk boyutu için 0,79 ve sağllk yoksunluğu boyutu için 0,73 olarak hesaplanmıştır. Ölçekte yer alan her madde için düzeltilmiş madde-toplam puan korelasyonları 0,40 ile 0,72 arasında hesaplanmıştır $(\mathrm{p}<0,05$; Tablo 5). Ölçeğin güvenirliği ile ilgili bulgular ölçeğin iç tutarlılığının tatmin edici düzeyde yüksek olduğunu göstermektedir.

\section{TARTIŞMA}

$\mathrm{Bu}$ çalışmanın amacı, yoksulluğun çok boyutluluğunu dikkate alarak birinci basamak sağlık hizmetlerinde maddi ve sosyal yoksunluğu belirlemek ve ölçmek üzere hazırlanan Birinci Basamak Sağlı Hizmetlerinde Yoksunluk Anketinin (DiPCare-Q) Türkçe versiyonunun geçerlik ve güvenirlik çalışmasını gerçekleştirmektir. Çalışma sonuçları DiPCareQ'nun sağlık kurumlarında yoksul hastaları belirlemek amaciyla Türkiye popülasyonunda kullanımının geçerli ve güvenilir olacağını göstermiştir. Psikometrik sonuçlar büyük ölçüde DiPCare-Q'nun geliştirildiği çalışmada bulunan sonuçlarla uyumludur. ${ }^{13}$ Kapsam geçerliğinin değerlendirilmesinde uzman görüşleri arasında uyum olduğu belirlenmiştir ve uzman görüşleri doğrultusunda gerekli düzeltmeler yapılmıştır. Ölçeğin yapı geçerliği için yapılan temel bileşenler faktör analizi sonuçları DiPCare-Q'nun 3 faktör ile toplam varyansın \%68,49'unu açıkladığını göstermektedir. Yordama geçerliği için yoksulluğun nesnel göstergelerine göre DiPCare-Q toplam ve alt boyut puan ortalamaları karşılaştırılmıştır. Karşılaştırma sonuçları DiPCare-Q'nun yoksulluğu belirlemede nesnel göstergelerin yerine kullanılabileceğini göstermiştir. Ölçeğin güvenirliğinin değerlendirilmesinde incelenen Kuder-Richardson 20 katsayıs 0,80 olarak hesaplanmış, ölçeğin güvenilir olduğu sonucuna ulaşılmıştır. Ayrıca maddelerin toplam puanla korelâsyonları da standart değer 0,40'ın üzerinde belirlenmiştir.

Türkçe yazılı kaynaklarda, sağlık hizmetlerinde yoksul bireyleri belirlemeye yönelik DiPCare-Q ya da benzer bir ölçeğin geçerlik-güvenirlik çalışmasına rastlanmamıştır. $\mathrm{Bu}$ nedenle ölçeğin geçerlik ve güvenirlik sonuçlarının karşılaştırılması mümkün olmamıştır.

DiPCare-Q'nun Türkçe uyarlaması yapılmadan önce, Türkiye'de birinci basamak sağlık hizmetlerinde yoksul bireyleri belirlemek üzere nesnel göstergeler dışında kullanılabilecek bir araç olup olmadığı araştırılmıştır. Ancak TÜİK'in gelir ve yaşam koşulları araştırmasında kullandığı maddi yoksunluğu belirlemeye yönelik yaşam standartları göstergelerinden farklı bir araca rastlanmamıştır. Çalışmanın giriş bölümünde de açıklandığı gibi yoksulluğu sadece maddi yoksunluk olarak görmek mümkün değildir. Sosyal eşitsizliklerle tanımlanan sosyal yoksunluğun özellikle dişlanma, izolasyon ve endişe gibi yarattığı sonuçların sağlık üzerindeki etkileri birçok çalışma ile ortaya konulmuştur. ${ }^{13,18,19}$ $\mathrm{Bu}$ bakış açısıyla sosyal yoksunluk, yoksulluğun önemli bir boyutudur ve maddi yoksunluktan ayrılması gerekmektedir. DiPCare-Q'nun geleneksel yoksulluk ve maddi yoksunluk ölçümleri 


\begin{tabular}{|c|c|c|c|c|}
\hline & $\begin{array}{c}\text { DiPCare-Q } \\
\text { Maddi } \\
\text { Yoksunluk } \\
\text { Boyutu }\end{array}$ & $\begin{array}{l}\text { DiPCare-Q Sosyal } \\
\text { Yoksunluk Boyutu }\end{array}$ & $\begin{array}{l}\text { DiPCare-Q Sağlık } \\
\text { Yoksunluğu Boyutu }\end{array}$ & DiPCare-Q Toplam \\
\hline TOPLAM & $3,55 \pm 2,42$ & $2,51 \pm 1,20$ & $0,51 \pm 0,59$ & $2,66 \pm 0,91$ \\
\hline \multicolumn{5}{|l|}{ Aylık hane halks geliri } \\
\hline 1.300 TL ve alt 1 & $5,51 \pm 2,50$ & $3,26 \pm 0,99$ & $1,00 \pm 0,30$ & $3,44 \pm 0,85$ \\
\hline $1.301-2.780 \mathrm{TL}$ & $3,80 \pm 1,95$ & $2,74 \pm 0,93$ & $0,64 \pm 0,16$ & $2,77 \pm 0,60$ \\
\hline $2.780-4.260 \mathrm{TL}$ & $1,68 \pm 1,26$ & $1,60 \pm 1,15$ & $0,46 \pm 0,15$ & $1,90 \pm 0,70$ \\
\hline 4.261 TL ve üstü & $0,71 \pm 0,75$ & $1,00 \pm 0,81$ & $0,40 \pm 0,37$ & $1,43 \pm 0,53$ \\
\hline$p$ & $0,000^{*}$ & $0,000 *$ & 0,183 & $0,000^{*}$ \\
\hline \multicolumn{5}{|l|}{ Ĕgitim düzeyi } \\
\hline Lise alt1 eğitimli & $3,90 \pm 2,47$ & $3,02 \pm 0,90$ & $0,58 \pm 0,61$ & $2,91 \pm 0,77$ \\
\hline Lise mezunu & $3,33 \pm 2,39$ & $1,94 \pm 1,20$ & $0,45 \pm 0,57$ & $2,45 \pm 1,00$ \\
\hline Yükseköğretim mezunu & $2,19 \pm 1,60$ & $1,31 \pm 1,13$ & $0,31 \pm 0,47$ & $1,81 \pm 0,75$ \\
\hline$p$ & $0,039 *$ & $0,000 *$ & 0,504 & $0,000^{*}$ \\
\hline \multicolumn{5}{|l|}{ Çalışma durumu } \\
\hline Çalıșıyor & $2,85 \pm 2,37$ & $2,28 \pm 1,32$ & $0,48 \pm 0,61$ & $2,44 \pm 0,94$ \\
\hline Çalışmıyor/ev hanımı & $4,27 \pm 2,27$ & $2,73 \pm 1,03$ & $0,54 \pm 0,57$ & $2,87 \pm 0,83$ \\
\hline$p$ & $0,001 *$ & $0,019 *$ & 0,492 & $0,001 *$ \\
\hline \multicolumn{5}{|l|}{ Konut mülkiyeti } \\
\hline Ev sahibi & $1,93 \pm 1,61$ & $2,17 \pm 1,21$ & $0,42 \pm 0,16$ & $2,20 \pm 0,72$ \\
\hline Kirac1/Diğer & $4,84 \pm 2,17$ & $2,78 \pm 1,13$ & $0,58 \pm 0,25$ & $3,02 \pm 0,89$ \\
\hline$p$ & $0,000 *$ & $0,001 *$ & 0,259 & $0,000 *$ \\
\hline \multicolumn{5}{|c|}{ Bir kurum ya da kişiden yardım alma } \\
\hline Evet & $5,86 \pm 1,67$ & $3,12 \pm 1,00$ & $0,74 \pm 0,65$ & $3,33 \pm 0,80$ \\
\hline Hayır & $2,70 \pm 2,08$ & $2,28 \pm 1,20$ & $0,43 \pm 0,54$ & $2,41 \pm 0,83$ \\
\hline$p$ & $0,000 *$ & $0,000 *$ & $0,020 *$ & $0,000 *$ \\
\hline \multicolumn{5}{|l|}{ Maddi yoksunluk } \\
\hline Evet & $1,20 \pm 1,26$ & $1,50 \pm 1,21$ & $0,40 \pm 0,15$ & $1,78 \pm 0,66$ \\
\hline Hayır & $4,33 \pm 2,20$ & $2,84 \pm 1,00$ & $0,55 \pm 0,23$ & $2,95 \pm 0,79$ \\
\hline$p$ & $0,000^{*}$ & $0,000 *$ & 0,404 & $0,000^{*}$ \\
\hline
\end{tabular}
$* \mathrm{p}<0,05$

Tablo 5. Ölçeğin Madde Toplam Puan Korelasyonu (r)

\begin{tabular}{|c|c|c|c|c|}
\hline & $\begin{array}{l}\text { DiPCare-Q Maddi } \\
\text { Yoksunluk Boyutu }\end{array}$ & $\begin{array}{l}\text { DiPCare-Q Sosyal } \\
\text { Yoksunluk Boyutu }\end{array}$ & $\begin{array}{c}\text { DiPCare-Q Sağlık } \\
\text { Yoksunluğu Boyutu }\end{array}$ & DiPCare-Q Toplam \\
\hline Madde 1 &, $800 *$ & & &, $666^{*}$ \\
\hline Madde 2 &, $549 *$ & & &, $472 *$ \\
\hline Madde 3 &, $578 *$ & & &, $537 *$ \\
\hline Madde 4 &, $628 *$ & & &, $582 *$ \\
\hline Madde 5 &, $575^{*}$ & & &, $582 *$ \\
\hline Madde 6 &, $473 *$ & & &, $413^{*}$ \\
\hline Madde 10 &, $546^{*}$ & & &, $483^{*}$ \\
\hline Madde 13 &, $843^{*}$ & & &, $719^{*}$ \\
\hline Madde 7 & &, $574 *$ & &, $529 *$ \\
\hline Madde 8 & &, $470^{*}$ & &, $438^{*}$ \\
\hline Madde 9 & & ,648* & & ,559* \\
\hline Madde 11 & & ,714* & &, $460 *$ \\
\hline Madde 12 & & ,407* & &, $458^{*}$ \\
\hline Madde 14 & & &, $504 *$ &, $453^{*}$ \\
\hline Madde 15 & & & ,408* &, $426^{*}$ \\
\hline Madde 16 & & & ,477* & ,408* \\
\hline
\end{tabular}


ile kıyaslandığında sübjektif sosyal durum ve yoksunluk durumu ile ilgili de önemli bilgiler sağladığını söylemek mümkündür.

Birinci basamak sağlik hizmetlerinde yoksul bireylerin belirlenmesi, sağlıkta eşitsizliklerinin giderilmesine yönelik çalışmalar geliştirmenin ilk adımıdır. Ancak hastanın yaşadığı ekonomik zorlukları bilmenin hekimin hasta ile kurduğu ile iletişimi de değiştirebileceğini ifade eden çalışmalar da mevcuttur. Eğer hekimler mevcut eşitsizliklere karşı hastanın lehine bir tavır sergiliyorsa, hastanın yoksulluk-yoksunluk durumunu belirlemek yararlı olacaktır. $^{20,21}$ Diğer taraftan hekimlerin yoksunluktan hoşlanmama eğilimi varsa sağlık eşitsizlikleri artabilir. Yoksulluğa verilecek uygun olmayan tepkilerin, yoksulluğun sağlık üzerindeki olumsuz etkilerini önlemek yerine önemli bir bariyer oluşturduğu kabul edilmektedir. ${ }^{22} \mathrm{Bu}$ durum hekimlerin bu tür bilgileri doğru olarak ele alma sorumluluğunu vurgulamaktadır. $\mathrm{Bu}$ nedenle, yoksunluğun belirlenmesi hekimlerin empati kurmalarını ve hastalarının faydasına davranışları benimsemelerini gerektirir. ${ }^{20}$

DiPCare-Q, yoksul bireylerin belirlenmesinde geçerli ve güvenilir bir veri toplama aracı olarak birçok çalışmada kullanılmıştır. ${ }^{23,24}$ Ancak Boyer ve arkadaşları (2014) internet erişiminin (madde 12) veya sinemaya gitmenin (madde 9) yoksulluğun işareti olmadığını, kişisel tercihi yansıtabileceğini belirtmektedir. ${ }^{12}$ Bahsedilen maddelerin DiPCareQ'da sosyal yoksunluk boyutunda değerlendirildiği ve sosyal yoksunluğun daha önce bahsedilen nedenlerle sağlık çıtıları üzerindeki kanıtlanmış etkisi düşünülürse bu eleştiriyi haklı olarak değerlendirmek mümkün değildir.

Çalışmanın bir takım sınırlılıkları bulunmaktadır. İlk olarak katılımcılardan tekrar ulaşmayı sağlayacak doğrultuda isim, adres vb. bilgilerin istenmesi veri toplamayı zorlaştırabileceği için çalışmada test-tekrar test güvenilirliği yapılamamıştır. Çalışmanın bir diğer sınırlılığı ise ASM'de verilerin toplanma sürecinde kişilerin hekimi ne zaman ziyaret ettiklerine dikkat edilmemiş, kişiler hizmet aldıktan sonra ya da almadan önce anket formunu doldurmuşlardır. $\mathrm{Bu}$ nedenle DiPCare-Q'nun sağlik yoksunluğu boyutunun hekimi ziyaret etmeden önceki yoksunluğu mu yoksa sonraki durumu mu yansıttığı

\section{KAYNAKLAR}

1. Institute of Medicine Study Committee. The Future of Public Health. 88(2). Washington, DC: National Academy Press; 1988. p.37.

2. Commission on Social Determinants of Health $(\mathrm{CSDH})$. Closing the Gap in a Generation: Health Equity through Action on the Social belirlenmemiştir. Son olarak faktör analizi için "madde sayısının 10 katı kuralı" sağlanmış olsa da, örneklem büyüklüğünün göreli olarak küçük olması bir diğer sınırlılıktır. Gelecek araştırmalarda bu sinırlılıkların dikkate alınması ve AFA ile ortaya konulan yapının doğrulayıcı faktör analizi ile test edilmesi yararlı olabilir. DiPCare-Q'nun kullanımı ile ilgili önemli bir nokta da teknolojide yaşanan hızlı gelişmeler internet erişiminin sosyoekonomik durumdan bağımsız olarak kolaylaşmasını sağlayabilir. Bu doğrultuda ölçekte yer alan 12 . maddenin (Son 1 ay içerisinde internet erişiminiz oldu mu?) zaman içerisinde güncellenmesi gerekebilir.

\section{SONUÇ}

Yoksulluğun ekonomik olarak önlenmesi mümkün olmasa da sağlık üzerindeki olumsuz etkilerini gidermek, sağlıkta eşitsizlikleri önleyebilmek, kalkınma perspektifinden birçok uluslararası kuruluşun ciddi olarak gündeminde yer almaktadır. $\mathrm{Bu}$ çalışmada birinci basamak sağlık hizmetlerinde yoksul bireylerin hızlı ve kolay bir şekilde belirlenmesi amacıyla geliştirilen Birinci Basamak Sağlık Hizmetlerinde Yoksunluk Anketinin Türkçe geçerlik güvenirliğini değerlendirmek amaçlanmıştır. Çalışmanın sonuçları, gelecekte klinik ve araştırma amaçlı olarak sağlık kurumlarında yoksul bireylerin belirlenmesine yönelik DiPCare-Q'nun kullanılabileceğini göstermiştir. Ayrıca sonuçların odak noktası yoksulluğun sadece maddi yoksunluk olarak değerlendirilmemesi gerekliliğini de vurgulamaktadır. $\mathrm{Bu}$ doğrultuda genel olarak yoksulluk ölçümlerinde daha spesifik olarak da sağlık hizmetlerinde yoksulları belirlemede sosyal yoksunluk ve sağlık yoksunluğunu da içerecek araçların, göstergelerin, ölçeklerin kullanılması önerilmektedir. DiPCare-Q ve benzeri ölçeklerin yoksulluğun nesnel göstergeleri ile belirlenebilen maddi yoksunluğun ötesinde sosyal yoksunluğu ve sağlık yoksunluğunu da belirleyebildiği görülmektedir. Bu çalışmada geçerlik ve güvenirlik çalışması yapılan DiPCare-Q'nun Türkçe formu, ülkemizde sağlık hizmetlerinde yoksul bireylerin belirlenmesi, yoksul bireylerinin sağlık ihtiyaçlarının karşılanması ve sonuç olarak sağlıkta eşitsizlikleri azaltmaya yönelik girişimlerin hayata geçirilmesi açısından önem taşımaktadır.

Determinants of Health. Final Report of the Commission on Social Determinants of Health. Geneva: World Health Organization; 2008. p.7.

3. Organisation for Economic Co-operation and Development (OECD). Development Cooperation Report 2013: Ending Poverty. OECD Publishing; 2013. p.19. DOI: 10.1787/dcr-2013en. 
4. World Health Organization (WHO) and World Bank. Dying for Change: Poor People's Experience of Health and Ill-Health. Washington DC: WHO/World Bank; 2002. p.6.

5. OECD and WHO. Poverty and Health. DAC Guidelines and Reference Series. France: OECD Publishing; 2003. p.20.

6. WHO. World Health Statistics 2015. Geneva: WHO; 2015. p.23.

7. Falkingham J, Namazie C. Measuring Health and Poverty: A Review of Approaches to Identifying the Poor. London: DFID Health Systems Resource Centre; 2002. p.7.

8. Sen A. Poor, relatively speaking. Oxford Econ Pap 1983; 35(2): 153-169. DOI: 10.1093/oxfordjournals.oep.a041587.

9. Sen A. Capability and well-being. In: Hausman DM, editor. The Philosophy of Economics. New York: Cambridge University Press; 1993. p. 270-293.

10. Zeumo VK, Tsoukiàs A, Somé B. A new methodology for multidimensional poverty measurement based on the capability approach. Socioecon Plann Sci 2014; 48: 273-289. DOI: 10.1016/j.seps.2014.04.002.

11. Barlas C, Şantaş FC, Kar AC. Türkiye'de bölgesel bebek ölüm hızlarının sağlık ekonomisi perspektifinden karşılaştırma analizi. International Conference On Eurasian Economies 2014. p. 1-10.

12. Boyer L, Baumstarck K, Iordanova $\mathrm{T}$, Fernandez J, Jean P, Auquier P. A povertyrelated quality of life questionnaire can help to detect health inequalities in emergency departments. J Clin Epidemiol 2014; 67 (3): 285-295. DOI: 10.1016/j.jclinepi.2013.07.021.

13. Vaucher P, Bischoff T, Diserens EA, Herzig L, Meystre-Agustoni G, Panese F. et al. Detecting and measuring deprivation in primary care: development, reliability and validity of a selfreported questionnaire: the DiPCare-Q. BMJ Open 2 2012: e000692. DOI: 10.1136/bmjopen2011-000692.

14. Taş R, editör. Ankara'nın Kentsel Yoksulluk Haritası. Ankara: Turgut Özal Üniversitesi Yayınlar1; 2012. p.44.

15. Field A. Discovering Statistics Using SPSS. London: SAGE Publications; 2009. p.647.

16. Türkiye İstatistik Kurumu. Gelir ve Yaşam Koşulları Araştırması, 2014. 18633 sayılı Haber Bülteni; 2015.

17. Aksayan S, Gözüm S. Kültürlerarası ölçek uyarlaması için rehber 1: Ölçek uyarlama aşamaları ve dil uyarlaması. Hemşirelik Araştırma Dergisi 2002; 4 (1):9-14.

18. Pantell M, Rehkopf D, Jutte D, Syme SL, Balmes J, Adler N. Social isolation: a predictor of mortality comparable to traditional clinical risk factors. Am J Public Health 2013; 103(11): 2056-2062. DOI: 10.2105/AJPH.2013.301261.
19. Valtorta NK, Kanaan M, Gilbody S, Ronzi S, Hanratty B. Loneliness and social isolation as risk factors for coronary heart disease and stroke: systematic review and meta-analysis of longitudinal observational studies. Heart 2016; 0:1-8. DOI: 10.1136/heartjnl-2015-308790.

20. Alexander GC, Casalino LP, Tseng CW, McFadden D, Meltzer DO. Barriers to patient physician communication about out-of-pocket costs. J Gen Intern Med 2004; 19:856e60. DOI: 10.1111/j.1525-1497.2004.30249.x.

21. Franks P, Fiscella K. Reducing disparities downstream: prospects and challenges. J Gen Intern Med 2008; 23:5; 672-677. DOI: 10.1007/s11606-008-0509-0.

22. Bloch G, Rozmovits L, Giambrone B. Barriers to primary care responsiveness to poverty as a risk factor for health. BMC Fam Pract 2011; 12: 62-67. DOI: 10.1186/1471-2296-12-62.

23. Bodenmann P, Favrat B, Wolff H, Guessous I, Panese F, Herzig L. et al. Screening primarycare patients forgoing health care for economic reasons. PLoS one 2014; 9(4): e94006. DOI: 10.1371/journal.pone.0094006.

24. Chatelard S, Bodenmann P, Vaucher P, Herzig L, Bischoff T, Burnand B. General practitioners can evaluate the material, social and health dimensions of patient social status. PloS one 2014; $9(1)$ : e84828. DOI:10.1371/journal.pone.0084828. 